\title{
Patients' follow-up using biomechanical analysis of rehabilitation exercises
}

\author{
Bruno Bonnechère ${ }^{1,2,3,4^{*}}$, Bart Jansen ${ }^{3,4}$, Lubos Omelina ${ }^{3,4,5}$, Victor Sholukha ${ }^{1,6}$, \\ Serge Van Sint Jan ${ }^{1,2}$. \\ ${ }^{1}$ Laboratory of Anatomy, Biomechanics and Organogenesis. Université Libre de Bruxelles. \\ Brussels, Belgium \\ ${ }^{2}$ Center for Functional Evaluation, Faculty of Medicine, Erasme Hospital, Université Libre \\ de Bruxelles, Brussels, Belgium \\ ${ }^{3}$ Department of Electronics and Informatics (ETRO). Vrije Universiteit Brussel Brussels, \\ Belgium \\ ${ }^{4}$ iMec, Kapeldreef 75, B-3001 Leuven, Belgium \\ ${ }^{5}$ Institute of Computer Science and Mathematics, Slovak University of Technology, \\ Bratislava, Slovakia \\ ${ }^{6}$ Department of Applied Mathematics, State Polytechnical University (SPbSPU), Saint- \\ Petersburg, Russia \\ \{bbonnech, vcholouk, sintjans\}@ulb.ac.be \\ \{bjansens, lomelina\}@etrovub.be
}

\section{Abstract}

Thanks to the evolution of game controllers video games are becoming more and more popular in physical rehabilitation. The integration of serious games in rehabilitation has been tested for various pathologies. Parallel to this clinical research, a lot of studies have been done in order to validate the use of these game controllers for simple biomechanical evaluation. Currently, it is thus possible to record the motions performed by the patients during serious gaming exercises for later analysis. Therefore, data collected during the exercises could be used for monitoring the evolution of the patients during long term rehabilitation. Before using the parameters extracted from the games to assess patients' evolution two important aspects must be verified: the reproducibility of measurement and a possible effect of learning of the task to be performed. Ten healthy adults played 9 sessions of specific games developed for rehabilitation over a 3-weeks period. Nineteen healthy children played 2 sessions to study the influence of age. Different parameters were extracted from the games: time, range of motion, reaching area. Results of this study indicates that it is possible to follow the evolution of the patients during the rehabilitation process. The majority of the learning effect occurred during the very first session. Therefore, in order to allow proper regular monitoring, the results of this first session should not be included in the follow-up of the patient.

Keywords: Serious games; new technology; assessment; biomechanical analysis

\section{Introduction}

Commercial video games have significantly evolved over the last decade. Today computer performance and play experience allow new perspectives for rehabilitation. Thanks to new gaming controllers (Nintendo Wii Fit ${ }^{\mathrm{TM}}$, Microsoft Xbox Kinect ${ }^{\mathrm{TM}}$, etc.) video game playing has changed from a passive (i.e., the player is seated on a sofa) to an active experience: players have to move in order to interact with games. 
Clinicians are now prospecting the new potential use of these games in rehabilitation mainly through testing available commercial games with patients suffering from various pathologies, mainly in the neurological field (e.g. cerebral palsy [1], stroke [2], Parkinson disease [3], elderly [4]...). The term serious gaming is used to describe the use of commercial games in rehabilitation. Physical rehabilitation must be based on active exercises, and these new gaming strategies allow for this. Currently there are two main limitations with the use of commercial video games in rehabilitation. First of all, these games are not adapted for rehabilitation (e.g. not based on physical rehabilitation exercises, based on speed, too complex visual background) since they are developed for fun and entertainment purposes. Therefore results of the clinical studies exploring the possibilities of the integration of such kind of exercises in physical rehabilitation did not, currently, present a high level of evidence [1][4].

Secondly, player motion accuracy requested by the player during the games is low while most therapists will aim to improve patient joint control and coordination. Furthermore, there is currently no possibility to record the motion performed by the patients during exercises. However, collecting this information could be important to: (i) allow to provide direct feedback to patient and eventually correct the motion if they are not performed in the right way and (ii) to provide information to therapists in case of telerehabilitation exercises when the patient is performing exercises at home without the clinicians' supervision [5].

In order to tackle the above mentioned limitations, specific games must be developed for rehabilitation purposes [6]. Such kind of games, called serious games (SG) (i.e. games designed with a primary purpose other than pure entertainment), must be designed taking into account real clinical needs and constraints (e.g. simple visual background, based on relevant clinical schemes, range of motion and speed required to perform the exercises must be adaptable...) [7] and allow to record motions performed by the patients [8].

Since the release of the Nintendo Wii Balance Board ${ }^{\mathrm{TM}}$ (WBB) and the Microsoft Xbox Kinect $^{\mathrm{TM}}$ (Kinect) in 2007 and 2010 respectively a lot of studies have been done in order to evaluate if these devices can be used to perform simple biomechanical evaluation (Kinect) and balance or posture assessment (WBB).

Concerning the WBB, several studies found good results for balance assessment in static condition [9][10] and for force estimation[11]. Therefore, the WBB is used in clinics with patients suffering from Parkinson's disease [12], orthopedic injuries (e.g. anterior cruciate ligaments injuries [13]) and with elderly patients [14][15]. Despite these studies the use of WBB in clinics is still controversial [16][17].

Concerning the Kinect, there are studies exploring the possibilities of this device for posture assessment [18], gait analysis [19], functional evaluation [20]. The Kinect is a markerless motion capture system that provides a simple skeleton model allowing full body analysis [21]. Such kind of system seems to be accurate enough to track and monitor patients body movements during simple rehabilitation exercises [8]. However, while results about repeatability of measurement performed with the Kinect are excellent [22], it appears that the skeleton model provided is not always stable and does not allow three-dimensional (3D) motion analysis (due to the small numbers of point) [20]. A model-based approach (MBA) has been developed in order to tackle these problems and allows 3D motion analysis with the Kinect [23].

It appears thus that specially developed SGs coupled to the WBB and the Kinect sensor could be used to follow patients' evolution during rehabilitation exercises [24]. However before being used in clinics to assess patients, the data collected during the games and parameters extracted from it must be repeatable from session to session or at least the progress made between the first and the last session due to a learning effect must be known. These data are important in order to quantify the part of the evolution of the patients due to clinical improvement and the part due to learning effect (if any).

Such kind of evaluation, done during the rehabilitation, has many advantages; (i) done in the natural environment of the patient (it is known that patients are not exhibiting the same performance when there are wearing underwear in a gait laboratory), (ii) when patients are immerged in the games they are less focused on the motion and on pain and can reach larger amplitudes than when there are asked to perform one particular motion, (iii) time saving and (iiii) financially beneficial (the devices are affordable and since the evaluation is done within the therapy session there is no dual pricing).

Therefore, the aim of this study was to evaluate the repeatability of the measurements collected during rehabilitation exercises performed by healthy subjects with the Kinect sensor and to quantify the learning effect in order to determine whether or not those parameters could be used to assess patient's status and follow up during the rehabilitation process. A second objective is to 
determine the evolution of the parameters collected during the exercises depending on the age of the participants.

\section{Material \& Method}

\subsection{Games}

Two specific SG have been developed (snapshots of the games are presented in Fig. 1 and 2, movies of the games can be seen from http://www.youtube.com/ict4rehab) [7]. During the Wipe Out game, patients must clean a screen covered by mud using a cloth (Fig. 1). During the Pirates game subjects have to conduct a pirate to a treasure following a predefined path, different configurations are possible (Fig. 2).

The Kinect was connected to a laptop (Intel Core I5, Windows 7, 6 GB RAM) via USB connection and data were retrieved using custom-written software based on the Kinect SDK [25]. All the data collected were stored in C3D file format (3D Biomechanics Data Standard).
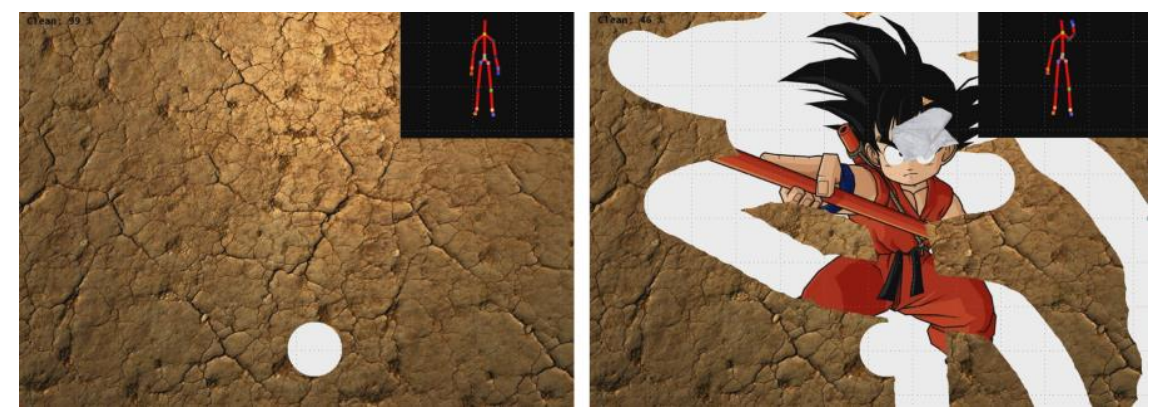

Figure 1. The Wipe Out games (the skeleton provided by the Kinect is shown in the right corner). Subjects have to clean $90 \%$ of the screen in order to compete the task.

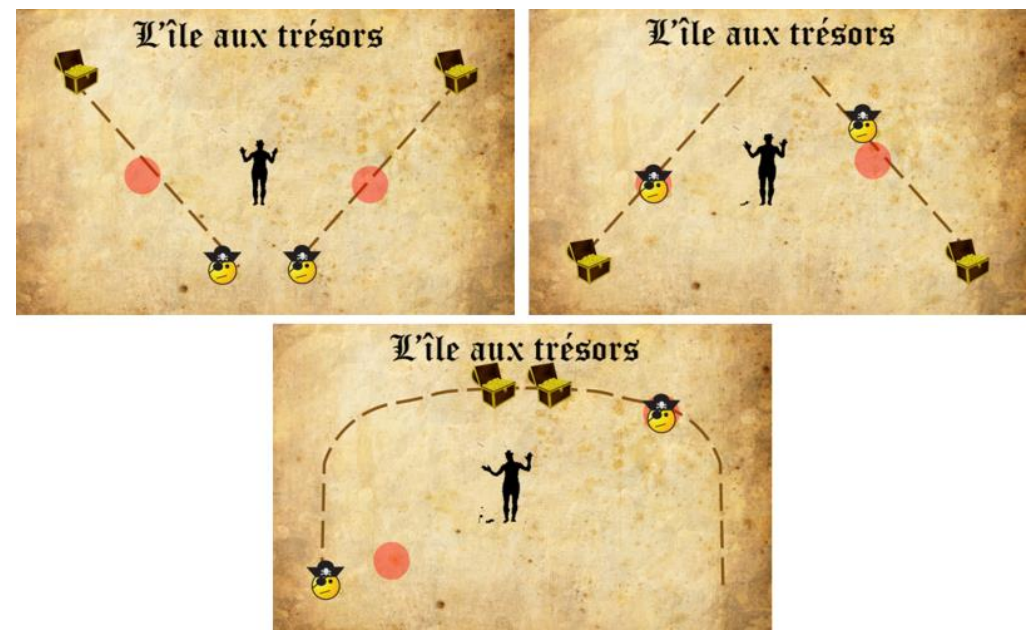

Figure 2. The three different configurations of the Pirate game used in this study. Subjects have to bring the pirate to the treasure following the path.

\subsection{Participants}

Ten young healthy adults (age $=26(4)$ years, height $=175(12) \mathrm{cm}$, weight $=65(12) \mathrm{kg}, 3$ females) and nineteen healthy children (age $=9$ (3) years, height $=133(17) \mathrm{cm}$, weight $=28(11) \mathrm{kg}, 3$ females) participated in this study, age repartition is presented in Table 1. No participant presented any neurological or orthopedic disorder and none of the subjects was taking medication at the time of the study that may have influenced balance, posture or limbs motions. This study was approved by the Ethical Committee of the Erasme Hospital (CCB: B406201525316) and written informed consent was obtained from all subjects prior to their participation. 


\subsection{Procedures}

The Kinect sensor was placed on a tripod at $1.5 \mathrm{~m}$ above the floor. Subjects stood at $2.5 \mathrm{~m}$ from the camera and the screen of the computer; this distance was found to provide optimal results in a previous study [26]. Installation of a subjects is presented in Figure 3

Subjects were then invited to play the games. Each session comprised the following games:

For the Wipe Out games three different configurations were used to control the cloth: with the upper limb, the lower limb and with the trunk. When the game is controlled with upper or lower limbs the screen is virtually divided into two parts. For each of the configurations 3 repetitions were performed in every session.

For the Pirate games two configurations were tested: with the upper limbs and with the lower limbs. As shown in Fig. 2 three different conditions were used: straight line from bottom to top (Configuration 1), straight line from top to bottom (Configuration 2) and curved path (Configuration 3). All of these configurations were symmetric. The three-different configurations were used in every session.

Both the order of the games and the order of the configuration within the game were randomized. The duration of a session was approximately 15 minutes (depending on the ability of the subject).

In total 9 sessions were played ( 3 sessions per week) using the same protocol for the adults and 2 sessions (one week intervals) for the children.

\subsection{Data processing}

Time required to succeed to perform a task is a good indicator of the global performance (e.g. gross motor function). Therefore, for both games the first parameter to analyze is the time required to perform the task (clean the screen or bring the pirate to the treasure).

In order to get more accurate and reliable results all the data collected with the Kinect were optimized using the developed Model Based Approach (MBA) [23]. Ranges of Motion (RoM=Maximal angle - Minimal angle) for 3D shoulder motions (flexion/extension abduction/adduction and rotations) and elbow flexion were processed for games controlled by upper limb and 3D hip motions (flexion/extension - abduction/adduction and rotations) and knee flexion for lower limb.

Then due to the different nature of the task, two different parameters were processed to get more information about the motions.

For the Wipe Out game the total length of the trajectory, the surface of the trajectory and the reaching area (i.e. the $3 \mathrm{D}$ envelop of the trajectory of the wrist related to the trunk or the foot related to the pelvis for upper and lower limb respectively). The reaching area is an important factor used in ergonomic to assess autonomy and functionality of the patients.

For the Pirate game another variable was computed to assess the quality and accuracy of the motion. For the upper limb motion of the wrist related to trunk along $Z$ axis (up and down displacement) and $X$ axis (medio-lateral displacement) were plotted and a polynomial fitting was applied ( $1^{\text {st }}$ degree for straight trajectories and $2^{\text {nd }}$ degree for curved one) to finally obtain the error estimate between the expected motion (trajectory on the screen and the one performed by the subject.

Ratios between right and left side were processed for all those parameters because many pathologies are asymmetric or affects only one side [27]. Therefore, it is important in clinics to quantify and compare the affected side related to the healthy one. Even for healthy subjects this ratio is important to determine if it is possible to detect difference between dominant and nondominant hand.

\subsection{Statistical analysis}

Normality of the data was checked using the Shapiro-Wilk test. Mean values and standard deviations were calculated. ANOVA tests for repeated measures were processed to compare the 9 sessions. In order to be more close to the clinical situation were testing is done before (pre-test) and after (post-test) the intervention, ANOVA tests were computed to compare results of the first and of the last session (noted "Pre-Post" in Tables 2-3-4). 
The test-retest reliability was investigated using Intra-class Coefficient Correlation (ICC) (two-way random average measures). All statistics and data processing were performed in Matlab (MathWorks, Natick, Massachusetts, U.S.A.).

\section{Results}

Results of the children were used to evaluate the effect of the age and maturity on the time required to perform these rehabilitation exercises.

Table 1 presents the results of the time required to perform the different configuration of the Wipe Out game according to the age of the participants.

Results of the biomechanical analysis used to perform the follow-up are presented for the adult's population (for clarity reason and due to space restriction).

Table 2 presents the results of the RoM reached during the different games (mean values of the different configuration and repetitions of the games), results of ANOVA tests (comparison of the ratio for the nine sessions), ICC is used to compare the nine sessions, Pre-Post is comparison between first and last session. The difference is the difference between session 1 and 9 expressed in percentage. For clarity and in order to avoid overloading the tables, only results of the first and the last sessions are presented. ANOVA and ICC have been processed on the ratio between left and right side for the nine sessions.

Finally results about the quality of the motion performed during the games are presented in Table 3 and Table 4 for the Pirate and the Wipe Out games respectively.

Table 1. Mean (std) results for the time required to perform the game (Wipe Out) for the three modalities according to the age of the participants, results are expressed in frames $(\approx 30$ frames/s).

\begin{tabular}{|c|c|c|c|c|c|c|c|c|}
\hline \multirow{2}{*}{$\begin{array}{c}\text { Wipe } \\
\text { Out }\end{array}$} & \multicolumn{8}{|c|}{ Age } \\
\hline & $5(5)$ & 7 (5) & $8(1)$ & $9(2)$ & $11(5)$ & $12(1)$ & $15(1)$ & $\begin{array}{l}\text { Adults } \\
\text { (10) }\end{array}$ \\
\hline Hands & $1462(274)$ & $1167(320)$ & $901(84)$ & $849(240)$ & $1048(512)$ & 762 (42) & 337 (66) & $584(154)$ \\
\hline Legs & $1470(580)$ & $1406(304)$ & $648(52)$ & $1090(236)$ & 1381 (532) & $966(113)$ & 962 (113) & 1097 (486) \\
\hline Trunk & $\begin{array}{c}4552 \\
(1118)\end{array}$ & $2124(714)$ & $2476(836)$ & $1974(775)$ & $1814(901)$ & $2028(466)$ & 802 (64) & $996(305)$ \\
\hline
\end{tabular}

\section{Discussion}

In this study three different approaches were tested to evaluate and assess players' abilities to perform correctly the rehabilitation exercises; (i) time analysis, (ii) biomechanical analysis and (iii) quality analysis.

Concerning the time analysis one example is presented in Fig. 3. ANOVA testing were applied to determine if the observed difference were statistically significant or not. For the three different configuration differences were observed. 


\section{Wipe Out Hands}

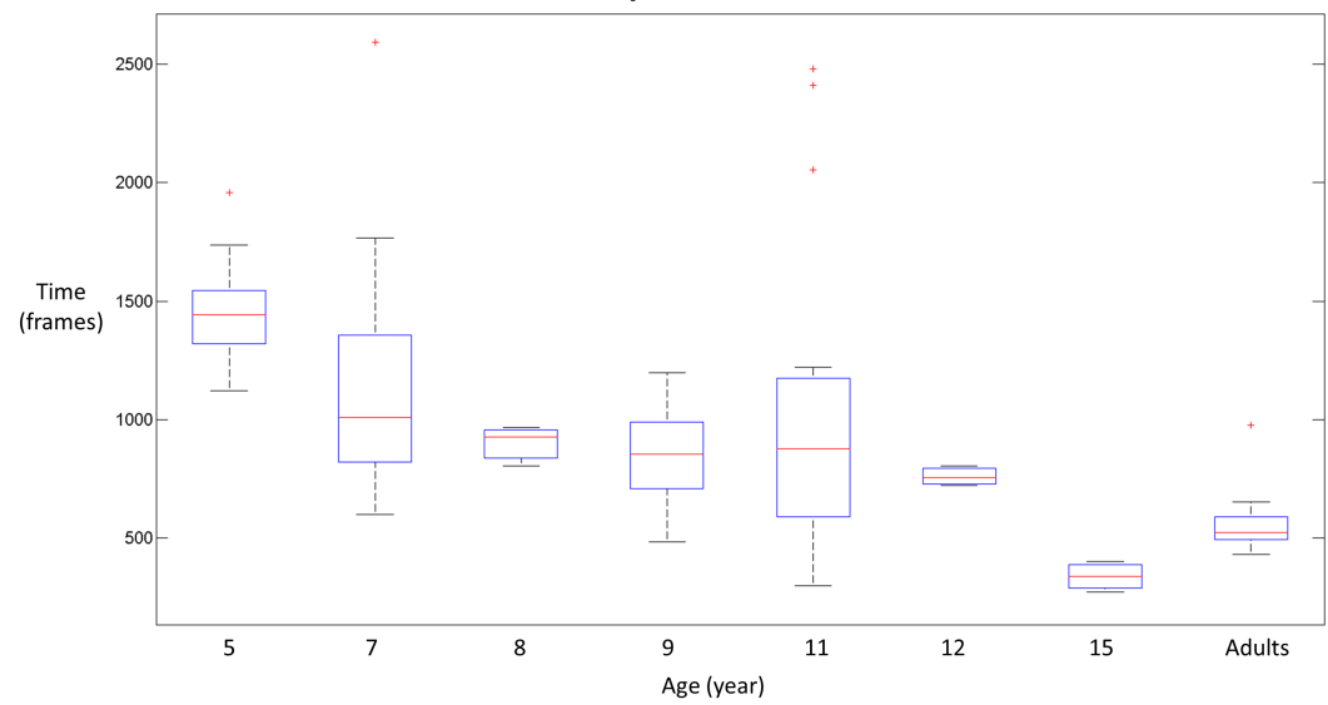

Figure 3. Evolution of the time required to perform the exercises according to the age of the participants for the Wipe Out controlled with the hands.

Table 2. Mean (std) results and statistics for range of motion, results are expressed in degrees.

\section{UPPER LIMB}

\begin{tabular}{|c|c|c|c|c|c|c|c|c|c|c|c|}
\hline & \multicolumn{3}{|c|}{ Left side } & \multicolumn{3}{|c|}{ Right side } & \multicolumn{4}{|c|}{ Ratio } \\
\hline & & $\begin{array}{c}\text { Session } \\
1\end{array}$ & $\begin{array}{c}\text { Session } \\
9\end{array}$ & $\begin{array}{c}T- \\
\text { test }\end{array}$ & $\begin{array}{c}\text { Session } \\
1\end{array}$ & $\begin{array}{c}\text { Session } \\
9\end{array}$ & $\begin{array}{c}T- \\
\text { test }\end{array}$ & ANOVA & $I C C$ & $\begin{array}{l}\text { Pre- } \\
\text { Post }\end{array}$ & Difference \\
\hline \multirow{4}{*}{ Pirate } & Flexion & $\begin{array}{l}106 \\
(18)\end{array}$ & $\begin{array}{l}101 \\
(14)\end{array}$ & 0.40 & $91(17)$ & $88(14)$ & 0.52 & 0.78 & 0.55 & 0.54 & $+1 \%$ \\
\hline & Abduction & $\begin{array}{l}102 \\
(33)\end{array}$ & $\begin{array}{l}104 \\
(34)\end{array}$ & 0.94 & $90(26)$ & $\begin{array}{l}102 \\
(25)\end{array}$ & 0.24 & 0.79 & 0.64 & 0.42 & $-10 \%$ \\
\hline & Rotation & $57(12)$ & $64(11)$ & 0.31 & $59(32)$ & $61(13)$ & 0.81 & 0.86 & 0.75 & 0.51 & $-8 \%$ \\
\hline & Elbow & $80(23)$ & $83(18)$ & 0.77 & $83(16)$ & $81(24)$ & 0.73 & 0.86 & 0.38 & 0.78 & $-6 \%$ \\
\hline \multirow{4}{*}{$\begin{array}{c}\text { Wipe } \\
\text { Out }\end{array}$} & Flexion & $\begin{array}{l}142 \\
(33)\end{array}$ & $\begin{array}{l}138 \\
(29)\end{array}$ & 0.78 & $\begin{array}{l}136 \\
(25)\end{array}$ & $\begin{array}{l}127 \\
(25)\end{array}$ & 0.39 & 0.09 & 0.44 & 0.35 & $-4 \%$ \\
\hline & Abduction & 84 (17) & $88(29)$ & 0.71 & $55(13)$ & $62(14)$ & 0.47 & 0.55 & 0.61 & 0.51 & $5 \%$ \\
\hline & Rotation & $57(18)$ & 60 (19) & 0.69 & $79(31)$ & $90(32)$ & 0.40 & 0.62 & 0.56 & 0.65 & $11 \%$ \\
\hline & Elbow & $88(28)$ & 99 (13) & 0.13 & $96(27)$ & $97(16)$ & 0.73 & 0.63 & 0.31 & 0.33 & $-11 \%$ \\
\hline
\end{tabular}

\section{LOWER LIMB}

\begin{tabular}{|c|c|c|c|c|c|c|c|c|c|c|c|}
\hline & \multicolumn{3}{|c|}{ Left side } & \multicolumn{3}{|c|}{ Right side } & \multicolumn{4}{|c|}{ Ratio } \\
\hline & & $\begin{array}{c}\text { Session } \\
1\end{array}$ & $\begin{array}{c}\text { Session } \\
9\end{array}$ & $\begin{array}{c}T- \\
\text { test }\end{array}$ & $\begin{array}{c}\text { Session } \\
1\end{array}$ & $\begin{array}{c}\text { Session } \\
9\end{array}$ & $\begin{array}{c}T- \\
\text { test }\end{array}$ & ANOVA & $I C C$ & $\begin{array}{l}\text { Pre- } \\
\text { Post }\end{array}$ & Difference \\
\hline \multirow{4}{*}{ Pirate } & Flexion & $95(14)$ & $\begin{array}{l}106 \\
(16)\end{array}$ & 0.22 & $98(30)$ & $96(21)$ & 0.88 & 0.69 & 0.55 & 0.21 & $-12 \%$ \\
\hline & Abduction & $91(44)$ & $95(22)$ & 0.84 & $\begin{array}{l}103 \\
(41)\end{array}$ & $\begin{array}{l}100 \\
(50)\end{array}$ & 0.93 & 0.31 & 0.44 & 0.77 & $-8 \%$ \\
\hline & Rotation & $42(14)$ & $50(15)$ & 0.15 & $42(12)$ & $48(14)$ & 0.43 & 0.08 & 0.42 & 0.33 & $-4 \%$ \\
\hline & Knee & $58(16)$ & $61(15)$ & 0.16 & $65(24)$ & $64(20)$ & 0.94 & 0.07 & 0.61 & 0.75 & $-7 \%$ \\
\hline \multirow{4}{*}{$\begin{array}{c}\text { Wipe } \\
\text { Out }\end{array}$} & Flexion & $60(15)$ & $56(13)$ & 0.61 & $61(14)$ & $57(13)$ & 0.63 & 0.67 & 0.12 & 0.78 & $0 \%$ \\
\hline & Abduction & $86(10)$ & $81(27)$ & 0.59 & 84 (17) & $72(21)$ & 0.31 & 0.28 & 0.27 & 0.64 & $-8 \%$ \\
\hline & Rotation & $37(8)$ & $32(13)$ & 0.40 & 45 (13) & $34(15)$ & 0.16 & 0.48 & 0.10 & 0.21 & $-15 \%$ \\
\hline & Knee & $84(29)$ & $75(30)$ & 0.56 & 74 (18) & $66(25)$ & 0.46 & 0.31 & 0.31 & 0.75 & $0 \%$ \\
\hline
\end{tabular}

Flexion, abduction and rotation are used for shoulder motions and for hip motions for upper limb and lower limb respectively.

Concerning biomechanical analysis, the different RoM reached during the game was analyzed. The first important points to note is that for all games and all configurations no statistical 
significant differences were found between all sessions (ANOVA) or between the first and the last session. Looking at the reproducibility of measurement two different patterns can be seen based on the different games. In the Pirate game the motion to perform is induced by the path and the player has to follow this trajectory, there is no flexibility. Higher ICC values were obtained for the Pirate games compared to the Wipe Out (mean ICC values $=0.58$ against 0.48 for the upper limb and mean ICC $=0.50$ against 0.20 for the lower limb). Although no difference was found in terms of RoM, results of the ICC seems to indicate that measuring only the RoM to define what has been done by a patient doing approximately $30 \mathrm{~s}$ of exercises is too simplistic. Therefore, more complex analysis must be performed in order to summarize and synthetize what the patient has been performing during the rehabilitation exercises.

Two different kinds of scores were thus computed, one for each game, in order to get information about the quality of the motion performed during the games.

The configuration used in the Pirate games was developed in order to assess symmetry between both sides and to quantify the severity of the disease compared to the healthy, or less severely affected side. From a therapeutic point of view there is still a debate about the use of symmetric or asymmetric exercises for the limbs [28], or to train only the affected side [29]. Contrariwise from the assessment point of view, due to high inter subjects variability, it is common to compare affected and healthy side. Results of the evolution of the ratio between right and left side are presented in Table 2 for the 3 different configurations tested. While only one statistical significant difference was found (hands, configuration 3) between session 1 and 9, both ANOVA and ICC results are low. Instead of computing the ratio, statistics on the learning effect were computed on each side separately.

Table 3. Mean (std) results and statistics for the quality score of the pirate game, ratios between right and left side are presented. The difference is the difference between session 1 and 9 expressed in percentage

\begin{tabular}{c|c|c|c|c|c|c|c}
\hline \multicolumn{2}{c}{ PIRATE } \\
\hline \multirow{3}{*}{ Hands } & Configuration & Session 1 & Session 9 & ANOVA & ICC & Pre-Post & Difference \\
\cline { 2 - 8 } & $\mathbf{I}$ & $117(23)$ & $116(31)$ & 0.96 & 0.20 & 0.98 & $0 \%$ \\
\cline { 2 - 8 } & $\mathbf{2}$ & $115(22)$ & $97(12)$ & $\mathbf{0 . 0 0 8}$ & 0.56 & 0.14 & $-15 \%$ \\
\hline \multirow{3}{*}{ Legs } & $\mathbf{3}$ & $95(17)$ & $118(24)$ & 0.66 & 0.48 & $\mathbf{0 . 0 4 *}$ & $+24 \% *$ \\
\cline { 2 - 8 } & $\mathbf{1}$ & $114(59)$ & $57(17)$ & $\mathbf{0 . 0 0 0 3}$ & 0.08 & 0.07 & $-50 \%$ \\
& $\mathbf{2}$ & $81(47)$ & $60(44)$ & 0.58 & 0.07 & 0.41 & $-26 \%$ \\
\hline
\end{tabular}

The Wipe Out game is less restrictive than the Pirate game since players are free to clean the screen without constraints. Therefore, scores relate to the trajectory path (length, surface and volume). No significant difference was found between the sessions, and good agreements were found for trajectory lengths and volume for both upper (ICC=0.60) and lower limbs (ICC=0.80). As for the time more reproducible results have been found for the lower limbs compared to upper limb.

In order to estimate the learning effect for every parameter the difference between results obtained during the second and the last sessions were computed since it appears that there is an important decrease between the first and the second session. The results are presented in the Table 5. ANOVA tests were used to determine if the observed difference was statistically significant or not. The learning effect is composed by two components: knowledge of the device (Kinect) but also the best and optimal way of moving to perform the games.

Table 4. Mean (std) results and statistics for the quality scores of the Wipe Out game. The difference is the difference between session 1 and 9 expressed in percentage

\begin{tabular}{c|c|c|c|c|c|c|c}
\hline \multicolumn{7}{c}{ WIPE OUT } \\
\hline \multirow{3}{*}{ Hands } & Parameters & Session 1 & Session 9 & ANOVA & ICC & Pre-Post & Difference \\
\cline { 2 - 8 } & Length, $\boldsymbol{c m}$ & $4779(3102)$ & $6195(1732)$ & 0.11 & 0.60 & 0.26 & $+30 \%$ \\
& Surface, $\boldsymbol{c m}^{2}$ & $2215(1531)$ & $2589(993)$ & 0.82 & 0.35 & 0.57 & $+17 \%$ \\
\cline { 2 - 8 } & Volume, $\boldsymbol{c m}^{3}$ & $24368(14332)$ & $24933(10399)$ & 0.69 & 0.59 & 0.93 & $+2 \%$ \\
\hline \multirow{3}{*}{ Legs } & Length, $\boldsymbol{c m}^{2}$ & $3800(2384)$ & $4632(3285)$ & 0.81 & 0.80 & 0.48 & $+22 \%$ \\
& Surface, $\boldsymbol{c m}^{2}$ & $2352(1322)$ & $2139(1068)$ & 0.11 & 0.42 & 0.61 & $-9 \%$ \\
& Volume, $\boldsymbol{c m}^{3}$ & $77710(8808)$ & $55540(5225)$ & 0.89 & 0.83 & 0.18 & $-28 \%$ \\
\hline
\end{tabular}


Table 5. Learning effect of the different studied parameters (computed between session 2 and 9)

\begin{tabular}{|c|c|c|}
\hline \multicolumn{2}{|c|}{ PARAMETERS } & Learning effect \\
\hline \multirow{5}{*}{ TIME TO ACCOMPLISH THE TASK } & Pirate - Hands & $-9 \%$ \\
\hline & Pirate - Legs & $-5 \%$ \\
\hline & Wipe Out - Hands & $-16 \%$ \\
\hline & Wipe Out - Legs & $-4 \%$ \\
\hline & Wipe Out - Trunk & $-19 \% * *$ \\
\hline \multirow{8}{*}{ ANGLES, UPPER LIMB } & Pirate - Shoulder Flexion & $+1 \%$ \\
\hline & Pirate - Shoulder Abduction & $-7 \%$ \\
\hline & Pirate - Shoulder Rotation & $-6 \%$ \\
\hline & Pirate - Elbow Flexion & $-7 \%$ \\
\hline & Wipe Out - Shoulder Flexion & $-3 \%$ \\
\hline & Wipe Out - Shoulder Abduction & $3 \%$ \\
\hline & Wipe Out - Shoulder Rotation & $8 \%$ \\
\hline & Wipe Out - Elbow Flexion & $-9 \%$ \\
\hline \multirow{8}{*}{ ANGLES, LOWER LIMB } & Pirate - Hip Flexion & $-10 \%$ \\
\hline & Pirate - Hip Abduction & $-6 \%$ \\
\hline & Pirate - Hip Rotation & $-4 \%$ \\
\hline & Pirate - Knee Flexion & $+2 \%$ \\
\hline & Wipe Out - Hip Flexion & $+1 \%$ \\
\hline & Wipe Out - Hip Abduction & $-6 \%$ \\
\hline & Wipe Out - Hip Rotation & $-11 \%$ \\
\hline & Wipe Out - Knee Flexion & $+2 \%$ \\
\hline \multirow{6}{*}{ QUALITY, PIRATE } & Upper Limb - 1 & $0 \%$ \\
\hline & Upper Limb - 2 & $-11 \%$ \\
\hline & Upper Limb - 3 & $-1 \%$ \\
\hline & Lower Limb - 1 & $-40 \% *$ \\
\hline & Lower Limb - 2 & $-23 \%$ \\
\hline & Lower Limb - 3 & $+2 \%$ \\
\hline \multirow{6}{*}{ QUALITY, WIPE OUT } & Upper Limb - Length & $+28 \%$ \\
\hline & Upper Limb - Surface & $+3 \%$ \\
\hline & Upper Limb - Volume & $-6 \%$ \\
\hline & Lower Limb - Length & $-9 \%$ \\
\hline & Lower Limb - Surface & $+21 \%$ \\
\hline & Lower Limb - Volume & $-19 \%$ \\
\hline
\end{tabular}

From the 33 parameters studied, only two of them presented significant differences between session 2 and 9 (the time for the Wipe Out with the trunk and the error estimation of the Pirate [configuration 1] controlled with the legs). However, some trends can be observed; a decrease in the time required to perform the exercises for all games (mean decrease of 10\%). Concerning the RoM no clear trend clearly appears, some joints presented increased amplitudes while other decreased. It is important to note here that, while for the time a decrease is expected as an indicator of progress in the games, for the RoM a better control of the motion does not necessarily imply an 
increase of amplitude. Actually, from a neurological rehabilitation point of view, by working on the quality of the motion, the coordination between both limbs increases, decreasing coupled motions, decreasing adiodochokinesia, the quantity of the motion (i.e. RoM) required is going to decrease and therefore the energy needed to perform this exercises will also decrease [30]. The different scores related to the quality have been developed for this purpose as an indicator of the efficiency of the motion.

\section{Conclusion}

This study focused only on a healthy population and would allow the creation of a database of healthy subjects for latter comparison with patients suffering from various pathologies. Therefore, further studies will focus on establishing a larger database with more children and elderly to analyze more particularly the influence of age on the developed parameters: from the acquisition and maturation of the control for the children until the deterioration caused by aging with the elderly.

To the authors best knowledge, the proposed solution is a unique and innovative approach that combined physical rehabilitation exercises with validated functional evaluation tools to assess and monitor patients' evolution during the rehabilitation process.

Future works will focus on patients suffering from various pathologies to analyze if the different scores computed are representative of the severity of the disease. Development of such kind of scores and of functional assessment performed during the rehabilitation exercises could offer new possibilities for both patients and clinicians involved in long term rehabilitation process. Intensity and required motions that need to be performed in order to control the games could be adapted from sessions to sessions in order to be perfectly adapted to the actual need and capacity of the patients and therefore be more effective for the patients. Future works are also needed to develop new games adapted for rehabilitation. Not only must the games be adapted for patients (speed, range of motion) but it is important to keep in mind that regular evaluation can be done with the SG. Therefore, it is important to find some parameters, relevant from a clinical point of view, that can be extracted from the games and from the motions that have been performed by the patients.

\section{References}

[1] Bonnechère, B., Jansen, B., Omelina, L., Degelaen, M., Wermenbol, V., Rooze, M., Van Sint Jan, S., "Can serious games be incorporated with conventional treatment of children with cerebral palsy? A review." Res Dev Disabil. vol 35(8), pp.1899-913. 2014 https://doi.org/10.1016/j.ridd.2014.04.016

[2] Putrino, D., "Telerehabilitation and emerging virtual reality approaches to stroke rehabilitation." Curr Opin Neurol. vol 27(6), pp. 631-6. 2014 https://doi.org/10.1097/WCO.0000000000000152

[3] Arias, P., Robles-García, V., Sanmartín, G., Flores, J., Cudeiro, J. "Virtual reality as a tool for evaluation of repetitive rhythmic movements in the elderly andParkinson's disease patients." PLoS One. vol 7(1), e30021. 2012 https://doi.org/10.1371/journal.pone.0030021

[4] Webster, D., Celik, O. "Systematic review of Kinect applications in elderly care and stroke rehabilitation." J Neuroeng Rehabil. vol 11, pp. 108-32. 2014 https://doi.org/10.1186/17430003-11-108

[5] Anton, D., Goni, A, Illarramendi, A. "Exercise recognition for Kinect-based Telerehabilitation". Methods Inf Med, vol 54(2), pp145-55. 2015 https://doi.org/10.3414/ME13-01-0109

[6] van Dooren, M., Visch, V., Spijkerman, R., Goossens, R., Hendriks, V. "Personalization in Game Design for Healthcare: a literature review on its definitions and effects". IJSG, vol 3(4), pp. 3-25. 2016 https://doi.org/10.17083/ijsg.v3i4.134

[7] Omelina, L., Jansen, B., Bonnechère, B., Van Sint Jan, S., Cornelis, J. "Serious games for physical rehabilitation : designing highly configurable and adaptable games." In Proc 9th Intl Conf. Disability, Virutal Reality \& Associated Technologies, Laval, France. 2012. 195-201

[8] van Diest, M., Stegenga, J., Wörtche, H.J., Postema, K., Verkerke, G.J., Lamoth, C.J.. "Suitability of Kinect for measuring whole body movement patterns during exergaming". J Biomech. Vol 47(12), pp.2925-32. 2014 https://doi.org/10.1016/j.jbiomech.2014.07.017 
[9] Clark, R.A., Bryant, A.L., Pua, Y., McCrory, P., Bennell, K., Hunt, M. Validity and reliability of the Nintendo Wii Balance Board for assessment of standing balance. Gait Posture. vol 31(3), pp. 307-10. 2010 https://doi.org/10.1016/j.gaitpost.2009.11.012

[10] Huurnink, A., Fransz, D.P., Kingma, I., van Dieën, J.H.. "Comparison of a laboratory grade force platform with a Nintendo Wii Balance Board on measurement of postural control in single-leg stance balance tasks". J Biomech. vol 46(7): pp.1392-5. 2013 https://doi.org/10.1016/j.jbiomech.2013.02.018

[11] Bartlett, H.L., Ting, L.H., Bingham, J.T.. "Accuracy of force and center of pressure measures of the Wii Balance Board". Gait Posture. vol 39(1), pp. 224-8. 2014 https://doi.org/10.1016/j.gaitpost.2013.07.010

[12] Holmes, J.D., Jenkins, M.E., Johnson, A.M., Hunt, M.A., Clark, R.A.. (2013) "Validity of the Nintendo $\mathrm{Wii}{ }^{\circledR}$ balance board for the assessment of standing balance in Parkinson's disease". Clin Rehabil. vol 27(4), pp. 361-6. 2013 https://doi.org/10.1177/0269215512458684

[13] Howells, B.E., Clark, R.A., Ardern, C.L., Bryant, A.L., Feller, J.A., Whitehead, T.S., Webster, K.E.. (2013) "The assessment of postural control and the influence of a secondary task in people with anterior cruciate ligament reconstructed knees using a Nintendo Wii Balance Board”. Br J Sports Med. vol 47(14), pp. 914-9. 2013 https://doi.org/10.1136/bjsports-2012091525

[14] Koslucher, F., Wade, M.G., Nelson, B., Lim, K., Chen, F.C., Stoffregen, T.A. (2012) "Nintendo Wii Balance Board is sensitive to effects of visual tasks on standing sway in healthy elderly adults". Gait Posture. vol 36(3), pp. 605-8. 2012 https://doi.org/10.1016/j.gaitpost.2012.05.027

[15] Young, W., Ferguson, S., Brault, S., Craig, C., "Assessing and training standing balance in older adults: a novel approach using the 'Nintendo Wii' Balance Board". Gait Posture. vol 33(2), pp. 303-5. 2011 https://doi.org/10.1016/j.gaitpost.2010.10.089

[16] Pagnacco, G., Bundle, M.W., Carrick, F.R., Wright, C.H., Oggero, E. "Letter to the editor: On "Validity and reliability of the Nintendo Wii Balance Board for assessment of standing balance" by R.A. Clark et al. [Gait \& Posture 31 (2010) 307-310]: are the conclusions stated by the authors justified?" Gait Posture. vol 39(4), pp. 1150-1. 2014

[17] Pagnacco, G., Wright, C.H., Oggero, E., Bundle, M.W., Carrick, F.R. "On "Comparison of a laboratory grade force platform with a Nintendo Wii Balance Board on measurement of postural control in single-leg stance balance tasks" by Huurnink, A., et al. [J. Biomech 46(7) (2013) 1392]: Are the conclusions stated by the authors justified?" J Biomech. vol 47(3), pp. 759-60. 2014 https://doi.org/10.1016/j.jbiomech.2013.06.039

[18] Clark, R.A., Pua, Y.H., Fortin, K., Ritchie, C., Webster, K.E., Denehy, L., Bryant, A. L."Validity of the Microsoft Kinect for assessment of postural control." Gait Posture. vol 36(3), pp. 372-7. 2012 https://doi.org/10.1016/j.gaitpost.2012.03.033

[19] Pfister, A., West, A.M., Bronner, S., Noah, J. A. "Comparative abilities of Microsoft Kinect and Vicon 3D motion capture for gait analysis". J Med Eng Technol.vol 38(5), pp. 274-80. 2014 https://doi.org/10.3109/03091902.2014.909540

[20] Bonnechère, B., Jansen, B., Salvia, P., Bouzahouene, H., Omelina, L., Moiseev, F., Sholukha, V., Cornelis, J., Rooze, M., Van Sint Jan, S. "Validity and reliability of the Kinect within functional assessment activities: comparison with standard stereophotogrammetry". Gait Posture. vol 39(1), pp. 593-8. 2014 https://doi.org/10.1016/j.gaitpost.2013.09.018

[21] González, A., Hayashibe, M., Bonnet, V., Fraisse, P. "Whole body center of mass estimation with portable sensors: using the statically equivalent serial chain and a Kinect". Sensors (Basel). vol 14(9), 16955-71. 2014 https://doi.org/10.3390/s140916955

[22] Bonnechère, B., Sholukha, V., Jansen, B., Omelina, L., Rooze, M., Van Sint Jan, S. "Determination of repeatability of kinect sensor." Telemed J E Health. vol 20(5), 451-3. 2014 https://doi.org/10.1089/tmj.2013.0247

[23] Sholukha, V., Bonnechère, B., Salvia, P., Moiseev, F., Rooze, M., Van Sint Jan, S. "Modelbased approach for human kinematics reconstruction from markerless and marker-based motion analysis systems." J Biomech. vol 46(14), 2363-71. 2013 https://doi.org/10.1016/j.jbiomech.2013.07.037

[24] Bonnechère, B., Jansen, B., Omelina, L., Da Silva L, Mouraux D, Rooze M, Van Sint Jan S. Patient follow-up using serious games : a feasability study on low back pain patients. in Games for Health, Edition : Springer, Editors : Schouten, B,, Fedtke, S,, Bekker, T, Schijven, M,, Gekker, A, pp.185-195 https://doi.org/10.1007/978-3-658-02897-8_14

[25] http://www.microsoft.com/en-us/kinectforwindows/develop/downloads-docs.aspx 
[26] Bonnechère, B., Jansen, B., Salvia, P., Bouzahouene, H., Sholukha, V., Cornelis, J., Rooze, M., Van Sint Jan, S. "Determination of the precision and accuracy of morphological measurements using the Kinect ${ }^{\mathrm{TM}}$ sensor: comparison with standard stereophotogrammetry." Ergonomics. vol 57(4), pp. 622-31. 2014 https://doi.org/10.1080/00140139.2014.884246

[27] Kagerer, F.A.. "Control of discrete bimanual movements: How each hand benefits from the other”. Neurosci Lett. vol 584, pp. 33-8. 2015 https://doi.org/10.1016/j.neulet.2014.10.002

[28] Lee, D., Lee, M., Lee, K., Song, C.. “Asymmetric training using virtual reality reflection equipment and the enhancement of upper limb function in stroke patients: a randomized controlled trial". J Stroke Cerebrovasc Dis. vol 23(6), pp. 1319-26. 2014 https://doi.org/10.1016/j.jstrokecerebrovasdis.2013.11.006

[29] van Delden, A.L., Beek, P.J, Roerdink, M., Kwakkel, G., Peper, C.L. "Unilateral and Bilateral Upper-Limb Training Interventions After Stroke Have Similar Effects on Bimanual Coupling Strength". Neurorehabil Neural Repair. [Epub ahead of print]. 2014

[30] Law, M.C., Darrah, J., Pollock, N., Wilson, B., Russell, D.J., Walter, S.D., Rosenbaum, P, Galuppi, B. "Focus on function: a cluster, randomized controlled trial comparing child- versus context-focused intervention for young children with cerebral palsy". Dev Med Child Neurol. vol 53(7), pp. 621-9. 2011 https://doi.org/10.1111/j.1469-8749.2011.03962.x 